$\xi=$ 国

\title{
Role of the St. Petersburg Paradox in Decision-Making
}

\author{
Mikhail Samuilovich Gasparian ${ }^{1 *}$, Irina Anatolievna Kiseleva ${ }^{1}$, Dmitry Gennadievich Korneev ${ }^{1}$, Sergey \\ Arkadyevich Lebedev", Viktor Arkadyevich Lebedev ${ }^{1}$

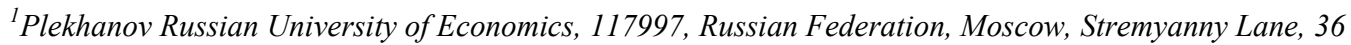 \\ *Corresponding author E-mail: mikhail_gasparian@mail.ru
}

\begin{abstract}
The article considers the appearance and modern interpretations of the St. Petersburg paradox. A review of the main solutions of the St. Petersburg paradox and an attempt to define their significance for the economic theory have been made. The impact of this problem on the economic theory can be seen by the example of such provisions as the principle of diminishing marginal utility, the use of expected utility as a criterion for decision-making in the context of uncertainty, as well as the basics of microeconomics of insurance and risk management, game theory, and some approaches to financial modeling.
\end{abstract}

Keywords: St. Petersburg paradox, decision-making, risk, risk assessment.

\section{Introduction}

Every day people have to choose in favor of one or another outcome, and this decision must necessarily be "correct." But what is included in this concept? What underlies the decisions made and what are the criteria for comparing different options? Another acute issue is whether people can make a proper rational choice or only come close to it. Besides, people have to make decisions in the context of risk and uncertainty in modern realities, and these factors play a direct role in determining the problems that a person faces. As a consequence, there is a common philosophical and methodological problem of decision-making in the context of uncertainty and risk. It triggered the emergence of multiple studies in the scientific field.

Before proceeding to the review of a decision-making model, some definitions should be given that will help better understand the logic of the established model. First of all, it must be noted that a decision is a process and a result of the choice of the goal, as well as the ways to achieve it. Besides, it serves as a link between the cognition and an option of human behavior. Decision-making includes such thinking processes as preliminary realization of the goal and ways of its implementation, as well as searching for various options. The decision-making involves knowledge, interests and mindset of the individual. A decision is a social concept accepted by one or more persons. It is not a secret that a human character is truly revealed through actions, and therefore the decision serves as the basis for self-identification. The first stage of decision-making is the emergence of an unfavorable, problematic situation, while the choice of a decision is the last stage, which is an action able to transform it.

This process can be shown as sequences of stages and procedures that have direct and feedback links between each other. The feedback links demonstrate the iterative, cyclical nature of the relationship between stages and procedures. Iterations in the implementation of the elements of the decision-making process are conditioned by the need for clarification and renewal of information after the subsequent actions.

\section{Concept of Risk and its Assessment}

The current society is often called a "risk society". The risk is an integral part of everyone's life today, because risky decisions to a certain degree must be taken every day, since the stochastic nature of social processes does not allow to confidently predict the future course of events. The risk in everyday life is usually understood as the possibility of the occurrence of an unfavorable event entailing the occurrence of various kinds of material or moral losses (physical injuries, loss of property, damage from natural disasters, etc.). As a rule, the signs and consequences of such events are known by precedent. The research finds that there are many definitions of the category of risk at the present time that reveal its essence from the standpoint of various sciences. The risk is also treated differently in economic sciences. For instance, in the economic theory, risk is considered to be a kind of "negative" product, which can be the object of free sale $[1,2]$. Risks are redistributed between the participants in the economic activity using various financial tools. At the same time, some participants insure themselves against risk by diversification and hedging of their portfolios, while others buy risk in order to secure a higher yield.

The risk in the financial theory is most often regarded as uncertainty in predicting the outcome of the transaction, the possibility of its deviation from the expected or planned value. Various definitions of financial risk can be found in [3-5].

Overall, it is generally accepted that risk is associated with uncertainty, which is heterogeneous both in form and in content. At a simple level, these two concepts are often the same. Analysis shows that such identification can also be found in financial literature $[6,3]$. However, despite the close relationship between these categories, in the opinion of the authors, their identification is completely unacceptable both from the theoretical and practical 
standpoint, since it assumes the similarity of the assessment and decision-making methods.

The quantitative assessment of the occurrence of possible events allows to conceptually distinguish between situations of risk and uncertainty. The risk situation is a kind of the situation of uncertainty, when the likelihood of implementing a decision can be assessed, taking into account the impact of natural factors, the actions of partners, competitors, etc. The risk situation includes a quantitative assessment of the likelihood of implementation and the implications of decisions made. The risk is an integral indicator that combines estimates of the likelihood of implementing the decision, as well as quantitative characteristics of its implications. [7, p. 35]. A person runs a risk when choosing an alternative that is a result of his or her decision, despite the fact that he or she does not know the exact result. An important issue is the possibility to measure risk, since it is impossible to make a rational choice from acceptable behaviors until the risk is assessed. A mathematical model is required for using quantitative methods of research, irrespective of the field of knowledge. When the model is built, the real phenomenon is simplified, schematized, and this model is described using certain mathematical toolkit.

The most successfully selected mathematical model that reflects the characteristic features of the phenomenon contributes to the emergence of the efficient recommendations resulting from its use.

The multiplication of the likelihood of a possible event by its result expressed in quantitative characteristics is one of the simple ways that allows to consider for the probabilities of possible events and implications associated with them. This product is also known as mathematical expectation of a possible random event. This algorithm of risk assessment is called the "payment matrix" method in the economic literature. However, this approach causes a paradox that has important methodological implications.

In the "payment matrix" method, the numerical risk assessment is the sum of the products of probabilities that the possible events may occur, as well as their numerical characteristics. Undoubtedly, the use of money as a universal numerical characteristic of possible outcomes is a natural way, because money is a measure of the value of goods and services, it expresses the value of all other goods and is exchanged for any of them. However, this approach, where the "risk price" is calculated in money, is not perfect and results in a paradox in reality. One of such known paradoxes is the St. Petersburg paradox.

\section{Emergence of the St. Petersburg Paradox and its Definition}

This problem was set and solved in the work of Daniel Bernoulli written in 1730 and published in 1738 [8, 9]. D. Bernoulli lived and worked in St. Petersburg at the time and published his work in "Notes of the Imperial Petersburg Academy of Sciences". This fact made the French mathematician J. d'Alembert call the problem "St. Petersburg" in 1768. This name was recorded in the history of mathematics and economics in the future.

The idea of the problem is as follows. A game is considered, which consists in sequential flipping a coin until it is "tails". If it is "heads" after the first flip, then the win is 1 currency unit (ducat, ecu, etc.), after the second flip it is 2 currency units, after the third -4 currency units, and etc. The question is how much money will be paid for participating in the game. In other words, a suitable model of the conditional situation presented above is a random variable $\bar{x}$ taking values $x_{k}=2^{k-1}, k \in N$ with probability $p_{k}=2^{-k}$ (the coin is symmetric). It is required to find a value which in a certain sense is equivalent to the indicated random variable.

The mathematical expectation was an accepted equivalent of random variables in the early XVIIIth century. These views arose from the unpublished correspondence between the French mathematicians B. Pascal and P. Fermat in 1654, as well as the treatise of the Dutch mathematician and physicist C. Huygens (1657), where the idea of mathematical expectation as a fair price for gambling was introduced.

But mathematical expectation for this problem is infinite

$E[\bar{x}]=\sum_{k=1}^{\infty} x_{k} * p_{k}=\sum_{k=1}^{\infty} 2^{k-1} * 2^{-k}=\sum_{k=1}^{\infty} \frac{1}{2}=\infty$

Naturally, the desire to give away an infinitely large amount for participating in gambling seemed unreasonable. As a result, the word "paradox" appeared in the name of the problem.

Daniel Bernoulli proposed to replace the value of the win with its usefulness. The scientist put forward the idea of using a logarithmic function. Then, after the appropriate transformation, it is as follows (2):

$$
\begin{aligned}
& \ln \bar{x}_{B}=\sum_{k=1}^{\infty} \ln \left(x_{k}\right) p_{k}=\sum_{k=1}^{\infty} \ln \left(2^{k-1}\right) 2^{-k}=\sum_{k=1}^{\infty} \frac{k-1}{2^{k}} \ln 2= \\
& \ln 2 \sum_{k=1}^{\infty} \frac{k-1}{2^{k}}=\ln 2
\end{aligned}
$$

As such, the equivalent sum is finite: $\bar{x}_{B}=2<\infty$

Besides, D. Bernoulli provides two solutions proposed by G. Kramer, which are based on the same method. In one of the solutions, Kramer proposes using the square root as the utility evaluation (in his terminology - "good", "moral value of goods"). Then it is as follows (3):

$\sqrt{\overline{x_{K_{1}}}}=\sum_{k=1}^{\infty} u\left(x_{k}\right) p_{k}=\sum_{k=1}^{\infty} 2 \frac{\sqrt{k-1}}{2}-k=\sum_{k=1}^{\infty} 2 \frac{-k+1}{2}=\frac{1}{2-\sqrt{2}}$

From which follows that $\bar{x}_{k_{1}}=2,9142$

Another solution of G. Kramer was based on the use of function $u_{d}(x)=\min \{x, d\}$, where it was suggested to take a sufficiently large $\mathrm{d}$ (for example, $\mathrm{d}=2^{24}$ ). In this case,

$u_{d}\left(\bar{x}_{K_{2}}=\sum_{k=1}^{\infty}\left(2^{k-1}\right) 2^{-k}=\sum_{k=1}^{2_{4}} \frac{2^{k-1}}{2^{k}}+\sum_{k=2_{5}}^{\infty} 2^{24-k}=24 *\right.$
$\frac{1}{2}+1=1_{3}$

Because $13<2^{24}, 3<2^{24}, \overline{x_{K_{2}}}=13$.

Applying modern concepts, it can be said that the utility function $\mathrm{u}(\mathrm{x})$ was introduced (different in each of the examples), through which the equivalent value was calculated using the following formula (5):

$u(\bar{x})=\sum_{k=1}^{\infty} u\left(x_{k}\right) p_{k}$

or in general form $u(\bar{x})=E[u(\bar{x}))]$.

In other words, the equivalent value was evaluated using the expected utility principle, and the value itself was equal to a reliable equivalent. This determines the classical nature of $\mathrm{D}$. Bernoulli's work.

\section{Overview of the key Solution of the St. Petersburg Paradox and their Significance for the Economic Theory}

The St. Petersburg paradox has been considered only in mathematical literature for a long time.

D'Alembert used it to criticize the probability theory, introducing various concepts related to the probability. Nevertheless, many authors of the XVIIIth - early XIXth century followed the logic of D. Bernoulli and began to oppose mathematical expectation to "moral expectation", i.e. the expected utility, in modern terms.

The mathematical papers of modern authors contain references to the St. Petersburg paradox. The problem is that some difficulties 
arise due to the random variables that have infinite moments of distribution, while the formulation of this paradox allows to discuss some solutions of such problems "by a simple example." For example, the law of large numbers in the standard formulation makes no sense for random variables with infinite mathematical expectation. But the corresponding result can be presented in special forms. Some of them take the properties of random variables into account, including the specificity of random variable from the St. Petersburg problem.

It cannot be asserted that the economists did not know the work of D. Bernoulli, but they did not realize the significance and economic problems of this work for a long time. For example, J.M. Keynes considered it in his "A Treatise on Probability", published in 1921. However, this was a mathematical rather than an economic work, the discussion related to the properties (criticism) of mathematical expectation, and Keynes rejected most of the proposed solutions of the paradox because "moral" considerations were used for them, rather than mathematical. Keynes proposed to use the following estimate (6):

$\sum_{k} p_{x}\left(x_{k}-E[\tilde{x}]\right)_{+}$,

where $(.)_{+}=\max \{0,$.$\} was a common function in modern$ models of evaluating the insurance and financial liabilities. J.M. Keynes used the term "risk" for it. In fact, this could be regarded as the introduction of a specific function $u\left(x_{k}\right)=\left(\llbracket x_{k}-\right.$ $E[\tilde{x}]) \rrbracket_{+6}$, although Keynes tried to oppose it to the theory of expected utility.

The opposition of "risk" to utility allowed to present D. Bernoulli and J. Keynes as the predecessors of the idea of "average - risk", known in assessing insurance and financial procedures, including in the portfolio theory.

The St. Petersburg paradox became common in the economic theory due to the Austrian, and later the American mathematician Carl Menger in the early XXth century $[10,11]$. A review article had been written by 1923 , being devoted to the main aspects of the solution of the St. Petersburg paradox. Then the economist introduced it in a 1927 report and published in 1934 in the major economic journal.

Menger showed the results already obtained by the time in this work but criticized the seeming paradox of the result and the solution proposed by D. Bernoulli and G. Cramer. C. Menger believed that the infinite mathematical expectation of winning was not paradoxical. In other words, he considers the mathematical expectation wider than the "fair price", i.e. as one of the forms of evaluation. According to $\mathrm{C}$. Manger, the real idea behind the paradox is that there is a discrepancy between the mathematical model and the observed behavior. This is why the analysis of the solutions of the St. Petersburg paradox, presented in his work, includes their interpretation from the standpoint of adequacy. It must be noted that Menger denoted the difference between the descriptive and normative (prescriptive) approach. The scientist adhered to the former approach, considering mathematical models as a convenient form of studying constant behavior, while also showing the possible limitations of their application. An important achievement of $\mathrm{C}$. Merger is that he shifted the emphasis from the search for a "fair price" to finding an adequate descriptive model of behavior in the context of uncertainty. He contributed to the introduction of the St. Petersburg paradox and related ideas in the economic theory.

The Menger's article largely contains an overview of the main solution of the St. Petersburg paradox existing in the mathematical literature and their characteristics from the standpoint of economic behavior. In addition, the mathematician offered opportunities to expand the analysis within the theory of expected utility. According to C. Menger, the solutions of the paradox can be divided into three groups [12]:

1. application of the theory of utility,

2. consideration of real world constraints, and

3. modification of probabilities.
The first group of solutions of the St. Petersburg paradox is related to the modification of the outcomes of a random variable using the function of utility. Besides, Menger provides some quotes that demonstrate how Bernoulli was followed by the established opinion about the need for this modification in the mathematical literature and shows its identity to the neoclassical approach, which rapidly developed at the time of writing his article.

However, Carl Menger focused his attention on the new aspect of the problem. He criticized his predecessors, making an emphasis on the case $u\left(x_{k}\right)=2^{k-1}$, for which the expected utility would be infinite, i.e. for such a case the modification of the outcome was insufficient. Menger believed that it was necessary to apply additional conditions to utility functions - for example, their limitation. P. Samuelson suggested calling the situation when utility grew very fast a "super-Petersburg game" [13].

To solve this problem, C. Menger refers to limited functions - for instance, hyperbolic, which was proposed by E. Timerding (7),

$u(x)=\frac{u_{\max x}}{u_{\max }+x}$

For which $u(0)=0, \lim _{x \rightarrow \infty} u(x)=u_{\text {max ии }} u(0)=1$.

However, Menger believed that such a proposal was not able to solve the emerging theoretical difficulties. This triggered a discussion about the necessary and sufficient conditions for the existence of utility functions in the second half of the XXth century. In particular, it was defined that an infinite (countable or uncountable) number of outcomes needed additional conditions, or axioms, which complicated the term of rationality, which had not yet been fully defined in the economic literature.

The restriction of the real world is the second group of solutions of the paradox, which does not allow achieving infinitely large sums, which brings the question of the result paradox to the question of the model adequacy. In particular, it is about the limited capital that can be used in the game, due to which the chain of flips cannot be too long. In fact, there is an alternative interpretation of the Cramer's second approach. However, while Cramer cited the formulation in terms of limited satisfaction, Menger spoke of the actual cap on capital available for the game.

The next type of practical restrictions that Menger notes is limited playing time, interrupting too long chains of the coin flips.

The limited time allowed D. Brito to interpret the St. Petersburg paradox in terms of G. Becker's theory of time allocation, linking the time and capital constraints at the optimal point of the mathematical problem of the consumer's behavior.

This constraint is coupled with the theoretical and probabilistic (frequency) argument discussed by Menger that the number of games that will actually take place is finite (or there can be only one game) so that the observed winnings will always be finite, as well as the sample mean, which is an empirical estimate of the mathematical expectation. This is why $\mathrm{C}$. Menger introduces a new economic concept of "willingness to pay", which plays an important role in the modern microeconomic pricing models.

This argument is supported by an empirical study of the French mathematician G.-L. de Buffon, which he described in his work "Essay on moral arithmetic" (1777) as an appendix to his fundamental work on natural history [14]. The study was 2,048 $\left(=2^{11}\right)$ tests of the St. Petersburg game. De Buffon did not receive chains longer than 9 , while the last ones were 6 . The average was 4.91 currency units.

This paper was the first published statistical experiment; the de Buffon's study preceded the emergence of an experimental economics. However, economists like H. Sauermann and R. Selten deny the fact that this study can be considered the first economic experiment, because no economic behavior was tested in it.

De Buffon explained the St. Petersburg paradox and his statistical experiment not from the standpoint of common sense (i.e. having in mind the limited number of flips), but assuming modification of probabilities, which he explained by moral reasons. 
This brings the research to the third group of solutions of the paradox.

The solution proposed in this approach can be mathematically represented as (8):

$p=\sum_{k=1}^{\infty} x_{k} \pi\left(p_{k}\right)$

where $\pi\left(p_{k}\right)$ is a suitable modification of the probability $\mathrm{p}_{\mathrm{k}}$, which secures the finality of the P estimation. In particular, de Buffon believed that the probabilities of very rare events were considered zero in decision-making. In fact, the normalization condition is violated with this modification, and a suitable multiplicative correction for the renormalization of the mass of probabilities should be introduced so that the values or $\pi\left(p_{k}\right)$ made a probability distribution.

This approach is also being developed in the modern economic science, despite the fact that there has been lately a trend of refraining from ignoring events that occur with small probabilities but cause critical damage. For example, the American economist Ch. Weber suggested introducing discount rates into the model in 1998 as a reflection of the fact that the game was being played in real time [15]. This is completely sufficient for the finiteness of the mathematical expectation and for the convergence of the series for the function of utility with the positive second derivative (i.e. for a person prone to risk). Despite the fact that the modification of the outcomes was popular, the criticism of the theories of expected utility in the second half of the XXth century contributed to countless attempts to generalize it, many of which included additional modification of probabilities. In particular, the theory of ranked expected utility can be mentioned as one of the most popular alternatives to the classical theory of expected utility. Another example of this kind is deformed distributions, which play a significant role in quantitative risk management. [16, p. 69; 17, p. 111].

The modern economic theory prefers using the following expected utility (9)

$u_{p}(\bar{x})=\sum_{k=1}^{\infty} u\left(x_{k}\right) \pi\left(p_{k}\right)$.

\section{Modern Interpretations of the St. Petersburg Paradox}

Several alternative interpretations of the St. Petersburg paradox were suggested in the second half of the XXth century, which concerned the behavior in financial markets. Some of them underlay alternative economic theories.

The outcome of the St. Petersburg paradox lies in the choice of probabilities of winning, other than $1 / 2$. In this case, the outcomes arise with probabilities subject to geometric distribution.

This is why D. Durand proposed to consider discount coefficients $v^{k}=(1+i)^{-k}$ instead of probabilities $\mathrm{p}_{\mathrm{k}}$, and coefficients of the company value increment $(1+g)^{k-1}$ instead of winnings $\mathrm{x}_{\mathrm{k}}$, assuming its growth with the constant rate of growth $g$. As such, the mathematical expectation of "winning" is infinite when $g \geq$ $i$. It is obvious that the application of the St. Petersburg game in this case is formal, because the discount coefficients are not probabilities. Besides, the sum of an infinite number of values $(1+g)^{-1}$ is not equal to one, so the condition of the "probability" normalization is violated. The risk is also ignored. D. Durand proposed to apply the corresponding value as one of the outcomes of random variable [18].

However, the resulting formula of the present value of the company discounted value is correct. The infinite value indicates the possibility of arbitrage transactions. This is why this result was used to explain participation in Ponzi schemes or behavior during bubbles, i.e. if the expected growth rate of asset value $g$ exceeds the current interest rate $i$, then the price for this asset can be set as high as it can be.

The investor's mistake is the assumption of an infinitely large or at least sufficiently long period of rapid growth.

Another financial interpretation, which is based on the presentation of the St. Petersburg game as a cash flow, is as follows: every "tails" at the k-th step means the need to pay a penalty of $2^{\mathrm{k}-1}$ by one player to the second one; when it's "heads", the opposite payment is made (from the second player to the first player), and the game ends. If it is "heads" at the n-th step, then the total payments of the first player to the second player will be $2^{n-1}-1$, his or her winnings will be $2^{n-1}$, so the net winnings are guaranteed to be 1 , which can be considered as the "price of the game" for the first player.

This transformation of the formulation of the St. Petersburg game is attributed to d'Alembert, thus, the corresponding strategy (for example, always betting on the same color and doubling the bet on loss in roulette) is called a system or a martingale of d'Alembert in the circle of professional casino players and financial speculators. However, the main problem of this approach is that the rate exponentially increases, and the money for the game can end very quickly [19].

There is also an interpretation based on the similarity of the utility function of D. Bernoulli and the information criterion for the entropy minimum proposed by C. E. Shannon. The academic advances and works of these two authors were completely independent. However, J. Kelly, reinforcing Shannon's argument, demonstrated an evaluation of the data transmission accuracy as a "game" in 1956, applying the sum (integral) of the logarithms of the capital values as a criterion. In fact, Kelly did not apply the idea of the utility function when finding the average growth rate (hence the logarithmic function). Despite the fact that the connection with gambling was external (terminological only), this approach had quickly spread among professional casino players and financial speculators under the name "Kelly criterion", and only after this its connection with the ideas of D. Bernoulli was realized [20, p. 72].

Meanwhile, the parallel of economic processes with statistical mechanics, which is based on the principle of entropy maximization, has facilitated the development of many areas in the economic theory. It was originally called "thermoeconomics" and was later divided into two branches. One was focused on the energy component in biological and social evolution, contributing to the emergence of a biophysical economy, while the other one focused on the use of the corresponding methods to solve economic problems, primarily related to the research into mass behavior in equilibrium situations and the evaluation of assets in financial markets. This branch was called "econophysics." Taking the realization of the relationship of these areas with the St. Petersburg paradox into account, the latter can be considered their remote predecessor, although not direct one [21, p. 42].

\section{Conclusion}

The St. Petersburg paradox is a mathematical problem in the field of the probability theory with artificial conditions. It is a predecessor of theories of the expected utility. The St. Petersburg paradox has played a key role in the development of several scientific dimensions, in particular the economic theory. Despite the fact that many scientists have not been fully aware of the economic content of this problem during the long years of discussions, they have proposed some approaches that are currently crucial for the microeconomic theory. This task was originally formulated and solved in the work of Daniel Bernoulli. However, the St. Petersburg paradox was introduced in the context of the economic theory in the early XXth century by the mathematician C. Menger, who shifted the emphasis from the search for a "fair price" to finding an adequate descriptive model of behavior in the context of uncertainty. 
The impact of this problem on the economic theory can be seen by the example of such ideas as the principle of diminishing marginal utility, use of expected utility as a criterion for decision-making in the context of uncertainty, and basics of microeconomics of insurance and risk management. [22, p. 12680; 23, p. 12658].

It played an important role in the emergence of the game theory [1]. The wide spread of the St. Petersburg paradox was manifested in the attempts to use it (often not fully justified) to substantiate some modern approaches to financial modeling. In particular, attempts were made to present it as a predecessor to the "average risk" concept actively used in the portfolio theory, as well as a precursor of econophysics, one of the popular alternatives to the modern financial theory.

\section{References}

[1] M.S. Nelyubina, Nestandartnyye zadachi teorii veroyatnostey [Nonstandard problems of the probability theory], Research and methodological electronic journal "Concept" 25 (2015) 236-240.

[2] V.S. Diev, Problema vybora i prinyatiya resheniya v mezhdistsiplinarnom kontekste [Problem of choice and decisionmaking in an interdisciplinary context], Bulletin of the Tomsk State University. Philosophy. Sociology. Political science 2 (22) (2014) 41-51.

[3] V.V. Kovalev, Korporativnyye finansy i uchet: ponyatiya, algoritmy, pokazateli [Corporate finance and accounting: concepts, algorithms, indicators]: Study guide. Part 1, Prospect, KNORUS, Moscow, 2014.

[4] A.A. Kudryavtsev, Sankt-Peterburgskiy paradoks i yego znacheniye dlya ekonomicheskoy teorii [St. Petersburg paradox and its significance for the economic theory], Bulletin of the SPSU 5(3) $201341-55$

[5] I.A. Kiseleva, N.E. Simonovich, Innovative methods of decisionmaking in the context of risks: psychological aspects, Agrarian education and science 2 (2016) 35 .

[6] I.A. Kiseleva, N.E. Simonovich, Competitiveness of an enterprise in the context of globalization of society: impact of the corporate culture, National interests: priorities and security 11 (2014) 39-44

[7] C. Menger, Selected texts, Territoriya budushchego, Moscow, 2005.

[8] D. Bernoulli, Opyt novoy teorii izmereniya zhrebiya [Practice of the new theory of the fortune measurement], Theory of consumer demand. SPb.: School of economics, 1993, pp. 11-27.

[9] P.A. Vatnik, Daniil Bernulli - economist [Daniel Bernoulli, an economist], Finance and business 2 (2008) 188-194.

[10] P. A Samuelson, St. Petersburg paradoxes: defanged, dissected and historically described, Journal of Economic Literature 15 (1977) 24-55.

[11] P. Weirich The St. Petersburg gamble and risk, Theory and Decision 17 (1984) 193-202.

[12] K. Menger, Das Unsicherheitsmoment in der Wertlehre, Zeitschrift für Nationalökonomie V(4) (1934) pp. 459-485.

[13] J. von Neumann, O. Morgenstern, Teoriya igr i ekonomicheskoye povedeniye [Theory of Games and economic behavior], Science, Moscow, 1970.

[14] B.B. Basaev, N.V. Gryzunova, I.A. Kiseleva, et al., The Role of Nonprofit Organizations in Alignment of Environmental Interests of Energy Companies and National Economic Security, International Journal of Environmental and Science Education 11(18) (2016) 12680-12689.

[15] M.V. Karmanov, A.V. Korotkov, N.V. Gryzunova, et al., The strategic analysis of industry-specific competition and environmental risks - an integrated approach, International Journal of Environmental and Science Education 11(18) (2016) 12657 12667.

[16] G.-L. de. Buffon, Essai d'arithmétique morale, Euvres complètes. T. XV, Verdière et Ladrange, Paris, 1829, 338-447.

[17] Ch. E. Weber, The St. Petersburg paradox: a resolution for impatient risk seekers, International advances in economic research 4 (1998) 367-373.

[18] J.Schumpeter, Istoriya ekonomicheskogo analiza [History of economic analysis], School of economics, St. Petersburg, 2001.

[19] A.P. Algin, Grani ekonomicheskogo riska [Patterns of economic risk], Knowledge, Moscow, 1991.

[20] C. Alexander, Financial Risk Management and Analysis. - Wiley, Chichester, 1996.
[21] E.J. Vaugham, Risk management, Wiley, New-York, 1997.

[22] A. Novoselov, I. Potravny, I. Novoselova, et al., Selection of priority investment projects for the development of the Russian Arctic, Polar Science 14 (2017) 68-77.

[23] V. Grachev, A. Novoselov, I. Novoselova, et al., New Methods of Assessing Damage to Environmental Pollution, Journal of Environmental Management and Tourism, 1(25) (2018) 105-113. 